\title{
Modelling the Effect of Road Excitation on Vehicle Suspension System
}

\author{
Robert Emmanuel Jonjo and Sahr Tamba Nyalloma
}

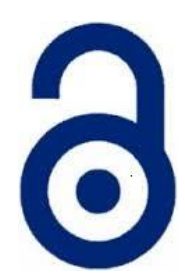

\author{
Received: 19 March 2020 \\ Accepted: 29 March 2020 \\ Published: 30 March 2020 \\ Publisher: Deer Hill Publications \\ (c) 2020 The Author(s) \\ Creative Commons: CC BY 4.0
}

\begin{abstract}
The vehicle suspension system serve a dual purpose - to provide passenger comfort and good road holding. In the design of a vehicle suspension system, these two contradictory criteria must be balanced out. Road irregularities are also a major source of anxiety amongst drivers and passengers alike. This research was undertaken to investigate the effect road irregularities will have on the vehicle structure especially the suspension system. In this study, the responses of different linear vehicle models are studied for step road input. The mathematical models considered are: a two degrees-of-freedom system (quarter car model) and a four degrees-of-freedom system (half car model). The equations of motion for both models were obtained using Newton's method. These models are analysed using SIMULINK/Matlab. Different response parameters such as the acceleration of the vehicle body and the travel of the suspension are investigated for a passive suspension system. The responses of the vehicle suspension due to changes in parameters such as suspension stiffness and damping coefficients are investigated. The results show that road irregularities affect the vehicle structures and the response of the suspension system is dependent on the suspension parameters. Passive suspension systems do not satisfy road holding and passenger comfort at the same time.
\end{abstract}

\section{INTRODUCTION}

The vehicle Suspension consists of springs, shock absorbers and other linkages that separates the car body from the car wheel. The functions of the automotive suspension on a vehicle includes; Isolating a car body from road irregularities, providing good handling by ensuring that roll and pitch motion are minimized and supporting the vehicle static weight. Vehicle suspension system should therefore isolate the vehicle body from road disturbances in order to give maximum passenger ride comfort whiles retaining continuous road-wheel contact so as to provide excellent road holding (Changizil and Rouhani 2011). It is therefore a challenge to design a vehicle to satisfy both ride comfort and road holding. Suspension systems are generally classified as passive, semi-active and active suspensions (Ghazaly and Moazz 2014, Tejas 2016)

- Passive suspensions: Passive suspension systems usually consist of a non-controlled spring and a damper with fixed parameters (Agharkakli .A 2012). They lack enough energy absorption capability to sustain the load input into the vehicle systems (Gao et al 2016). They lack stability when compared with other suspension systems (Dahunsi 2011).

- Semi-active suspensions: Semi active suspensions on the other hand provide a rapid change in rate of springs and damping coefficients. They usually have a fixed spring rate and a variable shock absorber. They do not provide any energy into suspension system. Compared to the active suspensions, these suspensions use less energy to operate and they are cheaper (Williams 1994).

- Active suspensions: The active vehicle suspension system employs electronic control systems that monitor the operation of the suspension elements. In active suspension systems, the shock absorber is replaced by a force actuator. They reduce car body accelerations by allowing the suspension to absorb wheel accelerations using an actuator (Pedro and Ekoru 2013). Unlike passive and semi-active suspensions, active suspensions give dynamic compensation (Kashem et al. 2012). They are Superior in performance than passive and semi-active suspension systems.

\section{MATHEMATICAL MODELING}

The three common vehicle models found in literature are the quarter car model (two degrees of freedom), the half car model (four degrees of freedom) and the full car model (seven degrees of freedom). Roll and pitch motions are

\section{R. E. Jonjo and S. T. Nyalloma $\triangle$}

Mechanical and Maintenance Engineering Department

Fourah Bay College, University of Sierra Leone

Barham Road, Southern Central, 00232

Freetown, Sierra Leon

E-mail: sahr.nyalloma@usl.edu.sl

Reference: Jonjo, R. E. and Nyalloma, S. T. (2020). Modelling the Effect of Road Excitation on Vehicle Suspension System. International Journal of Engineering Materials and Manufacture, 5(1), 19-28. 
ignored in the quarter car model. A half car model on the other hand considers either roll motion or pitch motion. The full car model considers roll, yaw and pitch motions.

\subsection{QUARTER CAR MODEL}

The quarter car model shown in Figure 1 is simple and widely used for dynamic performance analysis. It is a two degrees of freedom model. The quarter car model consists of one-fourth of the body mass, suspension components and one wheel. It represents the suspension system at any of the four wheels of the vehicle and the degrees-offreedom are displacement of axle and displacement of the vehicle body at a particular wheel. The assumptions of a quarter car modelling are as follows:

- The tire, spring and damper are modelled as a linear spring without damping,

- Rotational motion in wheel and body are ignored,

- The tire remains in contact with the road surface at all times

- Effect of friction between road and wheel is neglected.

Consider the free body diagram of the forces acting on the sprung mass as shown in Figure 2 with $Z_{s}>Z_{u}>Z_{r}$. The equation of motion of the sprung mass

$$
M_{S} \ddot{Z}_{S}+C_{S}\left(\dot{Z}_{S}-\dot{Z}_{U}\right)+K_{S}\left(Z_{S}-Z_{U}\right)=0
$$

Equation (i) can be rewritten as

$$
\ddot{Z}_{s}=\frac{1}{M_{S}}\left\{C_{S}\left(\dot{Z}_{u}-\dot{Z}_{s}\right)+K_{S}\left(Z_{u}-Z_{s}\right)\right\}
$$

Also, the free body diagram of the forces acting on the unsprung mass is shown in Figure 3 . The equation of motion of the unsprung mass becomes:

$$
M_{U} \ddot{Z}_{U}-C_{S}\left(\dot{Z}_{s}-\dot{Z}_{u}\right)-K_{S}\left(Z_{s}-Z_{u}\right)+K_{t}\left(Z_{u}-Z_{R}\right)=0
$$

Also, equation (iii) becomes;

$$
\ddot{Z}_{U}=\frac{1}{M_{U}}\left\{-C_{S}\left(\dot{Z}_{u}-\dot{Z}_{s}\right)-K_{S}\left(Z_{u}-Z_{s}\right)-K_{t}\left(Z_{u}-Z_{R}\right)\right.
$$

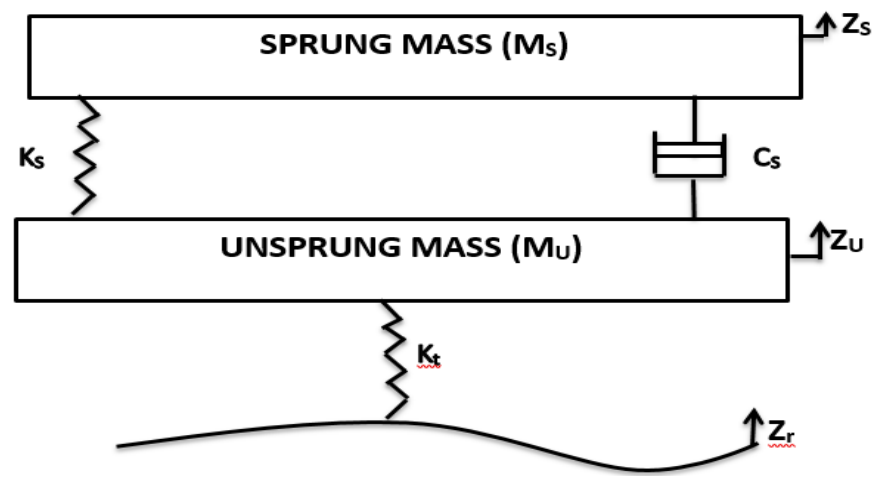

Figure 1. Quarter car model

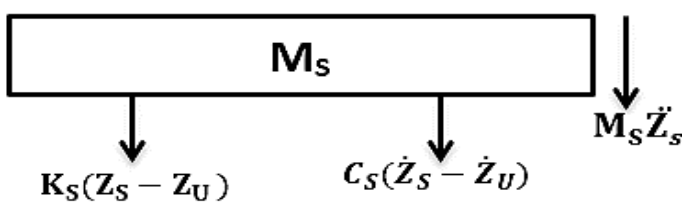

Figure 2. Forces acting on sprung mass for Quarter car model

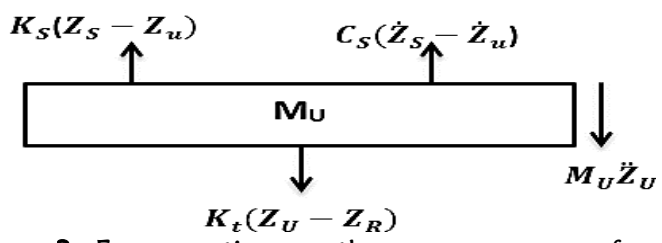

Figure 3. Forces acting on the unsprung mass for the Quarter car model

\subsection{HALF CAR MODEL}

The half car suspension model is a four degree of freedom system shown in Figure 4. This model considers both pitch and bounce motion of the vehicle. In this model, the following assumptions are made;

- The vehicle undergoes both pitch and bounce motion separately.

- The half car model can be a side, front or rear car model depending on the section of the vehicle considered. In this study, the side half car model will be considered.

- The tire, springs and dampers are modelled as a linear spring.

- The wheel is in contact with the road at all times. 
The free body diagram for both the sprung and unsprung masses with bounce and pitch motion is shown in Figures 5 and 6 . The equation of motion of the sprung mass exhibiting bounce motion is:

$$
M_{s} \ddot{Z}_{s}+C_{s r}\left(\dot{Z}_{s}-\dot{Z}_{u r}-C \dot{\theta}\right)+C_{s f}\left(\dot{Z}_{s}-\dot{Z}_{u f}+b \dot{\theta}\right)+K_{s r}\left(Z_{s}-Z_{u r}-C \theta\right)+K_{s f}\left(Z_{s}-Z_{u f}+b \theta\right)=0
$$

The equation of motion of the sprung mass exhibiting pitch motion is

$$
I \ddot{\theta}-C_{s r} C\left(\dot{Z}_{s}-\dot{Z}_{u r}-C \dot{\theta}\right)+C_{s f} b\left(\dot{Z}_{s}-\dot{Z}_{u f}+b \dot{\theta}\right)-K_{s r} C\left(Z_{s}-Z_{u r}-C \theta\right)+K_{s f} b\left(Z_{s}-Z_{u f}+b \theta\right)=0
$$

The equation of motion for both the front unsprung mass and rear unsprung mass are given respectively as,

$$
\begin{aligned}
& M_{u f} \ddot{Z} u f-C_{s f}\left(\dot{Z}_{s}-\dot{Z}_{u f}+b \dot{\theta}\right)-K_{s f}\left(Z_{s}-Z_{u f}+b \theta\right)+K_{t f}\left(Z_{u f}-Z_{r f}\right)=0 \\
& M_{u r} \ddot{Z}_{u r}-C_{s r}\left(\dot{Z}_{s}-\dot{Z}_{u r}-C \dot{\theta}\right)-K_{s r}\left(Z_{s}-Z_{u r}-C \theta\right)+K_{t r}\left(Z_{u r}-Z_{r r}\right)=0
\end{aligned}
$$

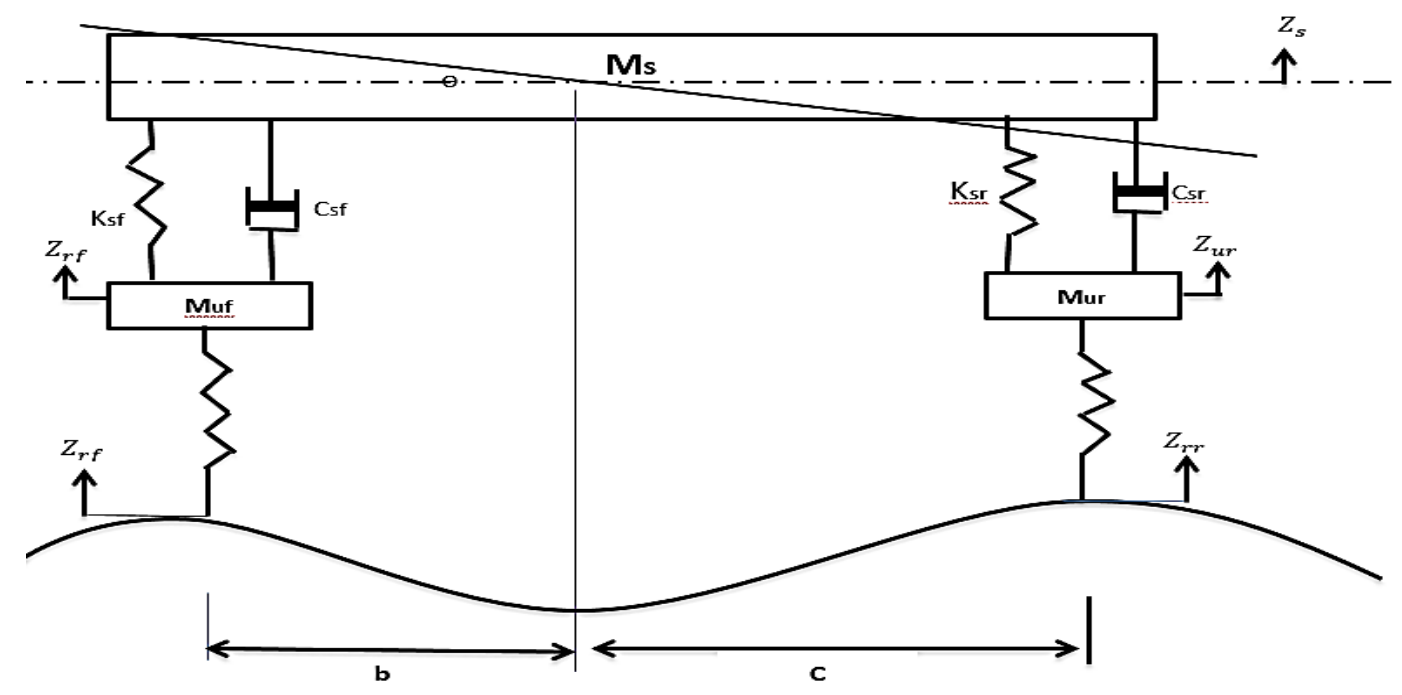

Figure 4. Half car model

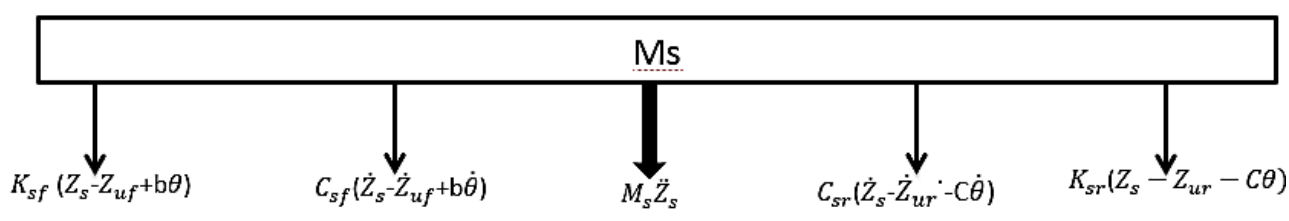

Figure 5. Free body for sprung mass exhibiting bounce motion

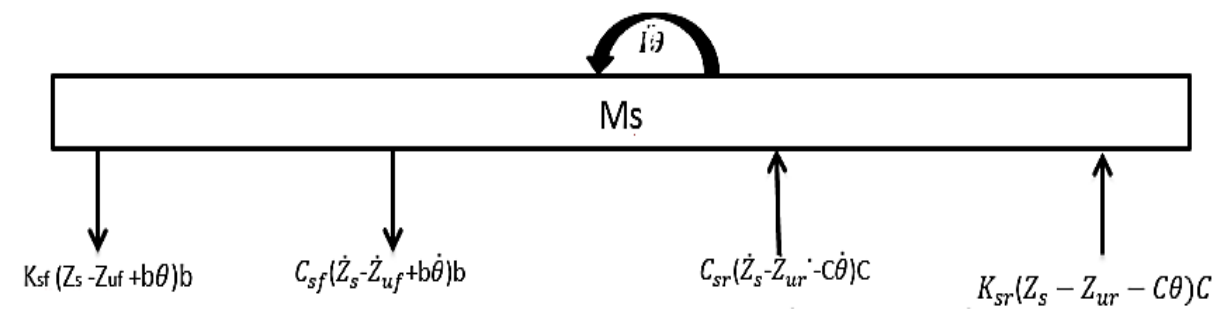

Figure 6. Free body diagram for sprung mass exhibiting (pitch motion)

\section{SIMULATION}

\subsection{Simulation Parameters}

In the current research vehicle parameters to undertake simulation of the quarter car and half car models were obtained for a passenger sedan as presented by (Agostinacchio et al. 2014) and presented in Tables one and two respectively. Road excitation input is a step signal of amplitude $10 \mathrm{~cm}$. 


\subsection{Simulation and Results}

The Simulink block diagram for the quarter car and half car models are shown in Figures 8 and 9 respectively. Both Figures represent the differential equations of motion for the two models investigated, that is, equations 2 and 4 for the quarter car model and equations 5, 6, 7 and 8 for the half car model.

Using the parameters presented in Tables 1 and 2, simulation of the system models was undertaken and the results presented in graphical format. The displacement of the vehicle body, displacement of the unsprung mass $(\mathrm{s})$, deflection of the wheels, suspension travel, acceleration of the car body in the vertical direction are the parameters that were investigated. The effect of the changes of various passive suspension parameters are investigated by keeping all other system parameters fixed and gradually varying the parameter being investigated.

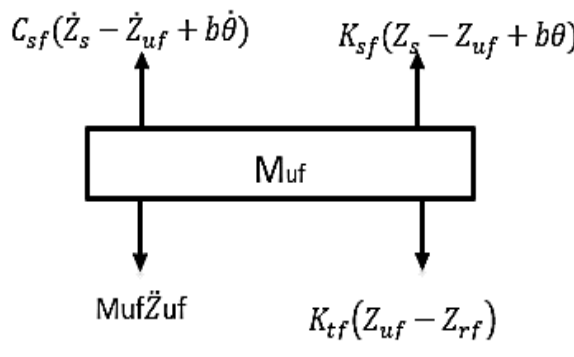

FRONT UNSPRUNG MASS

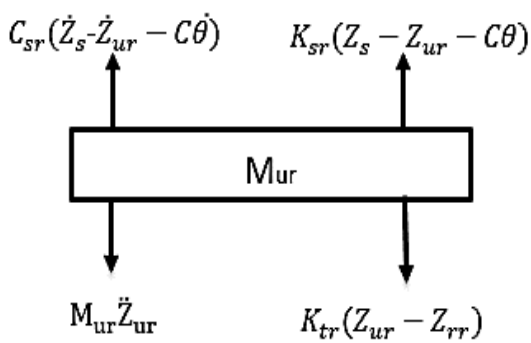

REAR UNSPRUNG MASS

Figure 7. Free body diagrams for front and rear unsprung mass

Table 1. Simulation parameters for Quarter car model

\begin{tabular}{lccc}
\hline Parameter & Symbol & Values & Unit \\
\hline Sprung mass of the vehicle & $M_{s}$ & 400 & $\mathrm{Kg}$ \\
Unsprung mass of vehicle & $M_{u}$ & 40 & $\mathrm{Kg}$ \\
Stiffness of tire & $K_{t}$ & 190000 & $\mathrm{~N} / \mathrm{m}$ \\
Spring constant of axle & $K_{s}$ & 21000 & $\mathrm{~N} / \mathrm{m}$ \\
Damping coefficient of axle & $C_{s}$ & 1000 & $\mathrm{Ns} / \mathrm{m}$ \\
\hline
\end{tabular}

Table 2. Simulation parameters for half car model

\begin{tabular}{lccc}
\hline Parameter & Symbol & Values & Unit \\
\hline Sprung mass of the vehicle & $M_{s}$ & 400 & $\mathrm{~kg}$ \\
Moment of inertia of vehicle & $I_{y}$ & 1100 & $\mathrm{kgm}^{2}$ \\
Unsprung mass of front axle & $M_{u f}$ & 40 & $\mathrm{~kg}$ \\
Unsprung mass of rear axle & $M_{u r}$ & 40 & $\mathrm{~kg}$ \\
Stiffness of front tire & $K_{t f}$ & 150000 & $\mathrm{~N} / \mathrm{m}$ \\
Stiffness of rear tire & $K_{t r}$ & 150000 & $\mathrm{~N} / \mathrm{m}$ \\
Spring constant of front axle & $K_{u f}$ & 21000 & $\mathrm{~N} / \mathrm{m}$ \\
Spring constant of rear axle & $K_{u r}$ & 21000 & $\mathrm{Ns} / \mathrm{m}$ \\
Damping coefficient of front axle & $C_{s f}$ & 1500 & $\mathrm{Ns} / \mathrm{m}$ \\
Damping coefficient of rear axle & $C_{s r}$ & 1500 & $\mathrm{~m}$ \\
Front body length from centre of gravity & $c$ & 1.47 & $\mathrm{~m}$ \\
Rear body length from centre of gravity & $b$ & 1.4 & \\
\hline
\end{tabular}




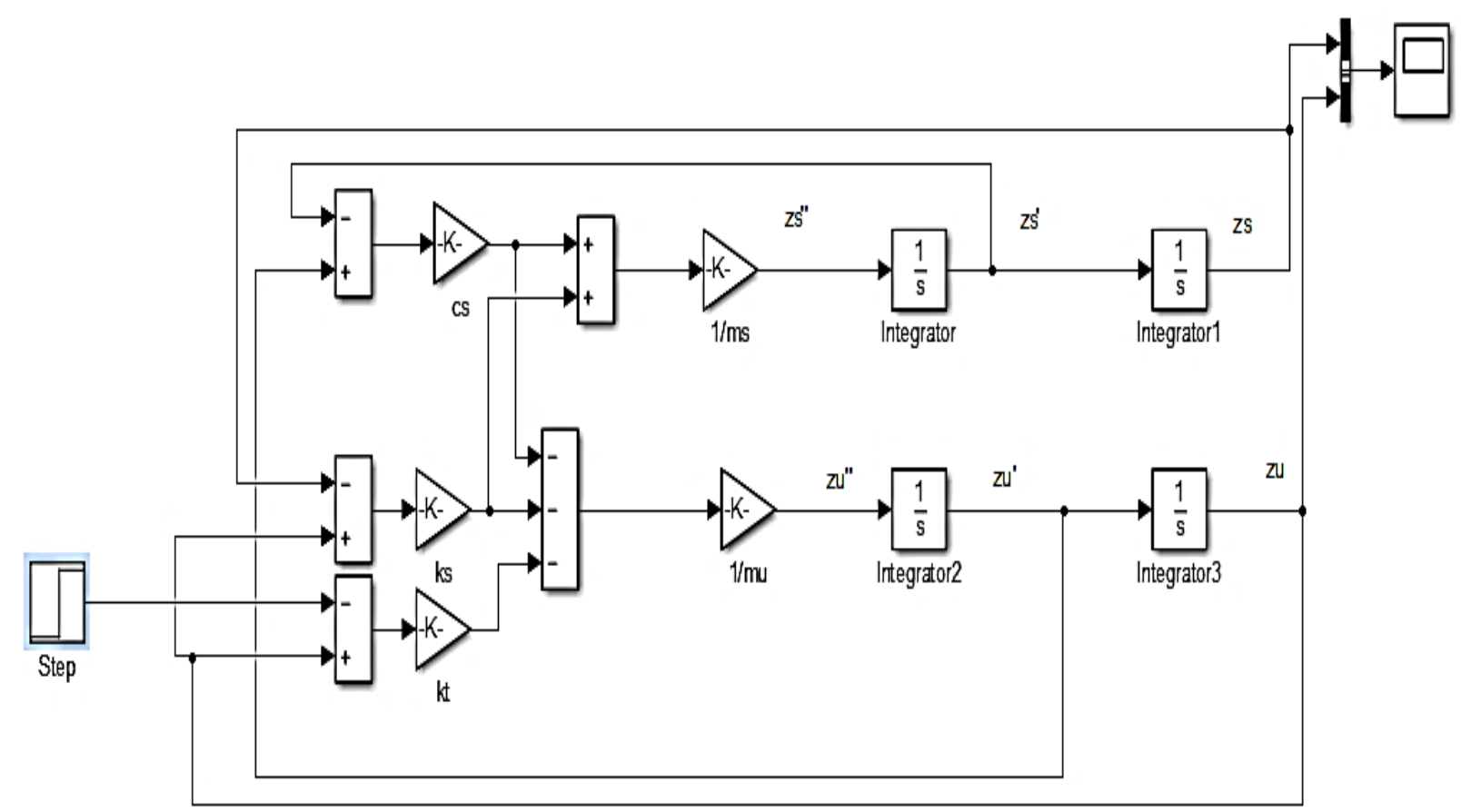

Figure 8. Simulink block diagram for quarter car model

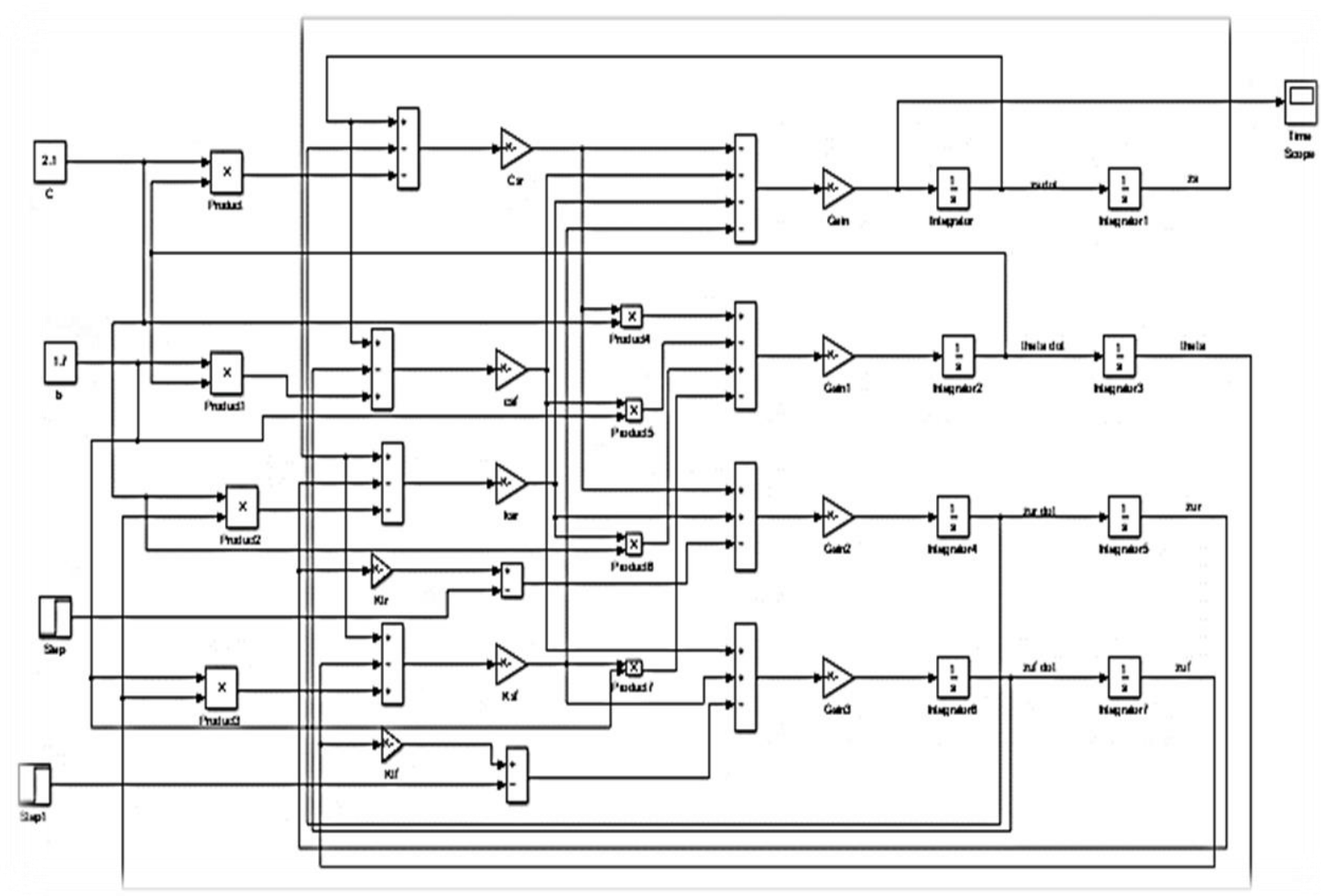

Figure 9. Simulink block diagram for half car model

\subsubsection{Simulation for Quarter Car Model}

The displacement of the sprung and unsprung masses, acceleration of the sprung and unsprung masses, suspension travel and tire deflection are presented in Table 3. Figures 10, 11 and 12 show the displacement of the sprung mass, acceleration and displacement of the unsprung mass for the quarter car model. 
Table 3. Simulation results for quarter car model

\begin{tabular}{|c|c|c|c|c|c|c|c|c|c|c|c|}
\hline No & Parameters & Values & $\begin{array}{l}\text { Maximum Sprung } \\
\text { Mass Displacement }\end{array}$ & $\begin{array}{l}\text { Maximum Unsprung } \\
\text { Mass Displacement }\end{array}$ & \multicolumn{2}{|c|}{$\begin{array}{l}\text { Sprung Mass } \\
\text { Acceleration }\end{array}$} & \multicolumn{2}{|c|}{ Suspension Travel } & \multicolumn{2}{|c|}{ Wheel Deflection } & $\begin{array}{c}\text { Rms } \\
\text { Acceleration }\end{array}$ \\
\hline 1 & \multirow{4}{*}{$\begin{array}{l}\text { Sprung } \\
\text { Mass }\end{array}$} & 400 & 0.1569 & 0.1268 & 16.776 & -2.969 & 0.050 & -0.115 & 0.0268 & -0.100 & 0.5829 \\
\hline 2 & & 500 & 0.1601 & 0.1258 & 13.569 & -2.439 & 0.053 & -0.113 & 0.0258 & -0.100 & 0.472 \\
\hline 3 & & 1000 & 0.1686 & 0.1238 & 6.920 & -1.329 & 0.059 & -0.1175 & 0.0238 & -0.100 & 0.253 \\
\hline 4 & & 1500 & 0.1730 & 0.1231 & 4.643 & -0.923 & 0.064 & -0.1189 & 0.0231 & -0.100 & 0.178 \\
\hline 5 & \multirow{4}{*}{$\begin{array}{l}\text { Unsprung } \\
\text { Mass }\end{array}$} & 50 & 0.1576 & 0.1309 & 15.796 & -3.436 & 0.049 & -0.1125 & 0.0309 & -0.100 & 0.582 \\
\hline 6 & & 100 & 0.1584 & 0.1433 & 13.045 & -5.056 & 0.051 & -0.1161 & 0.0433 & -0.100 & 0.586 \\
\hline 7 & & 150 & 0.1599 & 0.1461 & 11.452 & -5.420 & 0.062 & -0.1180 & 0.0426 & -0.100 & 0.597 \\
\hline 8 & & 200 & 0.1631 & 0.1539 & 10.622 & -6.335 & 0.067 & -0.112 & 0.0534 & -0.100 & 0.593 \\
\hline 9 & \multirow{4}{*}{$\begin{array}{l}\text { Suspension } \\
\text { Stiffness }\end{array}$} & 21000 & 0.1569 & 0.1268 & 16.776 & -2.959 & 0.050 & -0.1115 & 0.0268 & -0.100 & 0.5829 \\
\hline 10 & & 30000 & 0.1646 & 0.1217 & 17.858 & -4.346 & 0.054 & -0.1059 & 0.0217 & -0.100 & 0.639 \\
\hline 11 & & 40000 & 0.1709 & 0.1164 & 19.010 & -5.892 & 0.055 & -0.099 & 0.0164 & -0.100 & 0.704 \\
\hline 12 & & 60000 & 0.1750 & 0.1197 & 20.139 & -7.330 & 0.056 & -0.095 & 0.0197 & -0.100 & 0.791 \\
\hline 13 & \multirow{4}{*}{$\begin{array}{l}\text { Damping } \\
\text { Coefficient }\end{array}$} & 1500 & 0.1569 & 0.1268 & 16.776 & -2.959 & 0.050 & -0.115 & 0.0268 & -0.100 & 0.5829 \\
\hline 14 & & 2000 & 0.1492 & 0.1188 & 18.998 & -3.200 & 0.043 & -0.099 & 0.0188 & -0.100 & 0.659 \\
\hline 15 & & 2500 & 0.1421 & 0.1120 & 20.023 & -3.195 & 0.037 & -0.091 & 0.0120 & -0.100 & 0.749 \\
\hline 16 & & 3000 & 0.1381 & 0.1100 & 22.478 & -3.542 & 0.038 & -0.0828 & 0.0108 & -0.100 & 0.786 \\
\hline 17 & \multirow{4}{*}{$\begin{array}{c}\text { Tire } \\
\text { Stiffness }\end{array}$} & 150000 & 0.1569 & 0.1268 & 16.776 & -2.959 & 0.050 & -0.1115 & 0.0268 & -0.100 & 0.5829 \\
\hline 18 & & 200000 & 0.1555 & 0.1310 & 19.880 & -5.183 & 0.050 & -0.1205 & 0.031 & -0.100 & 0.629 \\
\hline 19 & & 250000 & 0.1542 & 0.1388 & 23.220 & -7.252 & 0.050 & -0.1278 & 0.0388 & -0.100 & 0.680 \\
\hline 20 & & 300000 & 0.1535 & 0.1439 & 26.143 & -8.821 & 0.049 & -0.1324 & 0.0439 & -0.100 & 0.747 \\
\hline
\end{tabular}




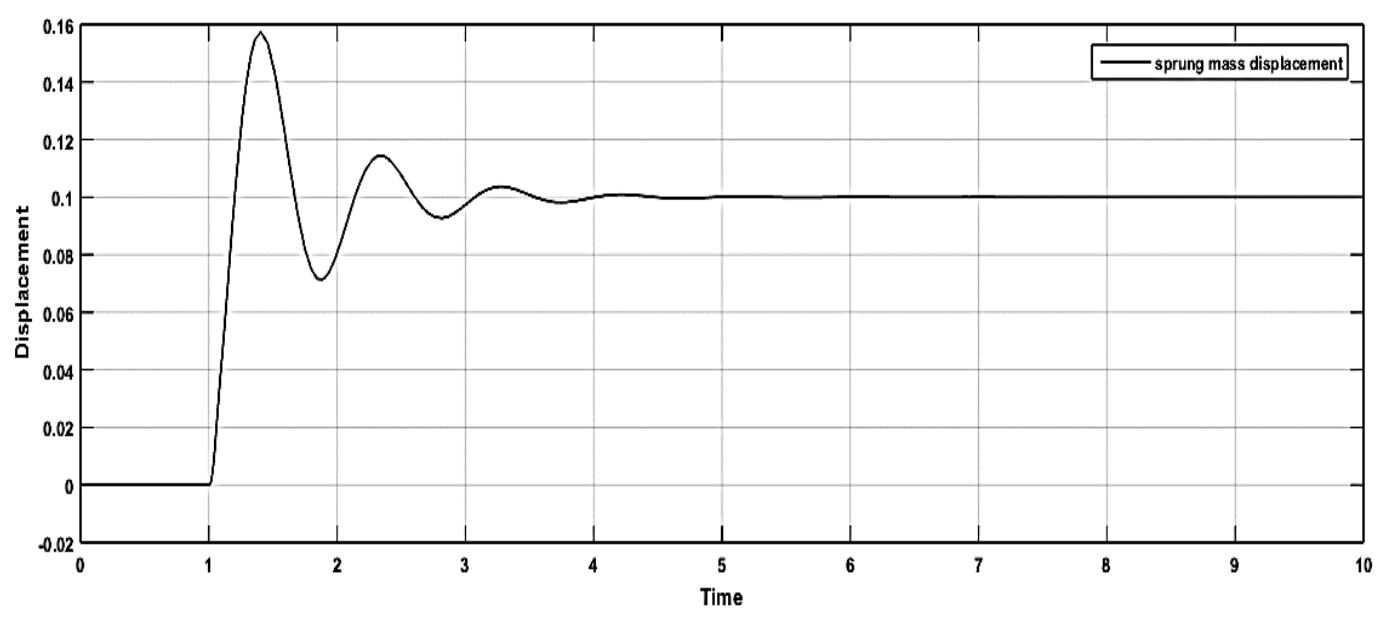

Figure 10. Displacement of the sprung mass Quarter car model

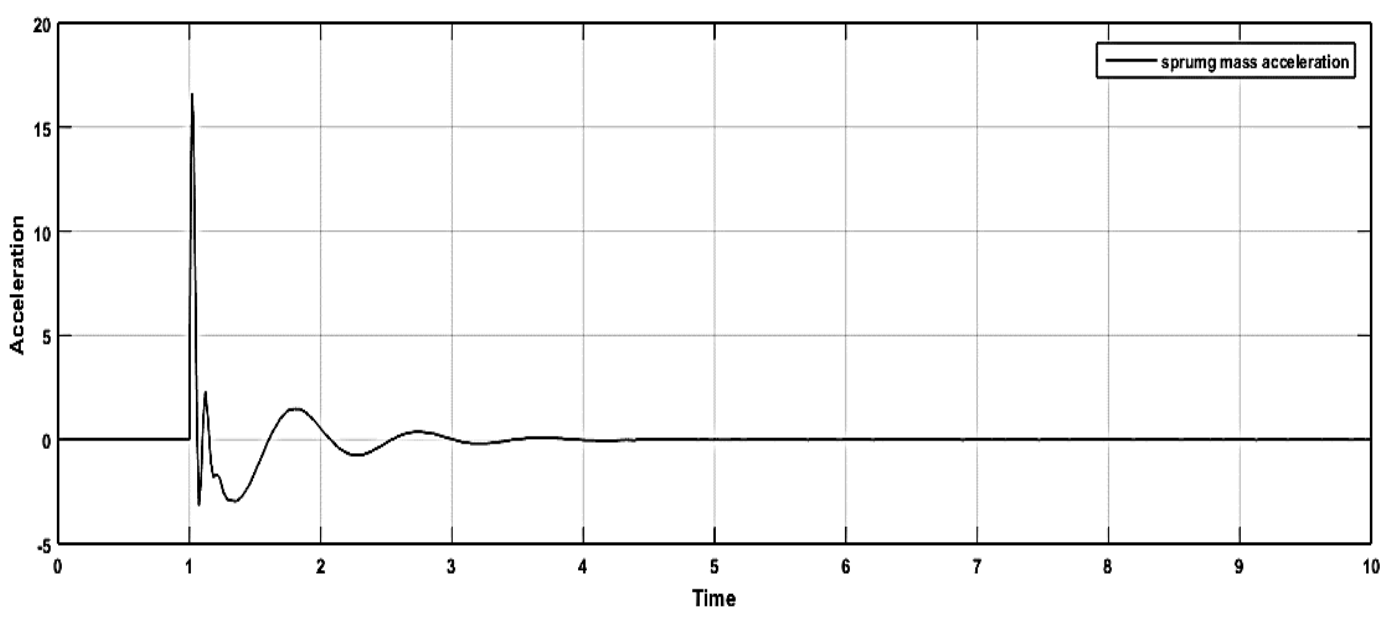

Figure 11. Acceleration of sprung mass Quarter car model

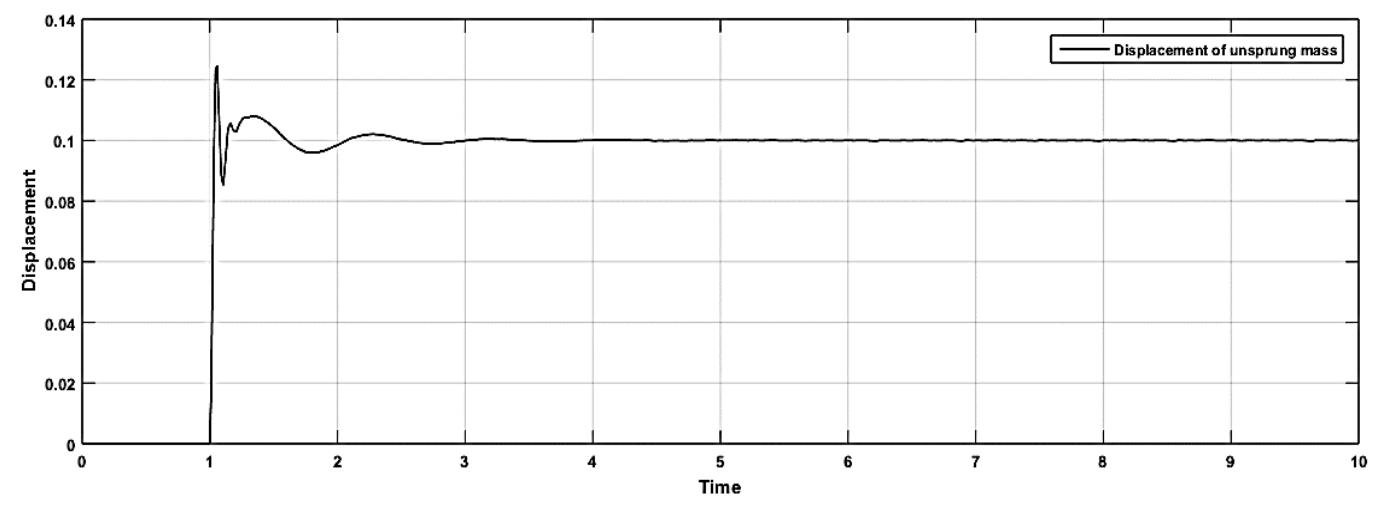

Figure 12. Displacement of the unsprung mass 


\subsubsection{Simulation for Half Car Model}

The simulation results for the Half- Car model is presented in Table 4. Figures 13, 14 and 15 show the displacement of the sprung mass, and the displacement of the unsprung masses for the half - car model.

\section{RESULTS}

Simulations were carried out for the Quarter car and Half- car models. Different response properties were investigated such as vehicle sprung mass displacement, unsprung mass displacement, suspension travel, wheel deflection. From the simulation results presented in Tables 3 and 4, it is observed that the vehicle experiences a vertical acceleration as it passes over a road irregularity. The following general observations are made from the simulation results.

From the simulation results it is evidently clear that an increase in the sprung mass leads to a lower vertical acceleration of the car body, an increase in the vertical displacement of the car body and an increase in the suspension travel. If all other parameters are kept constant whiles the unsprung mass(es) is gradually increased, similar trends are observed as in the case of the sprung mass. Vertical acceleration is reduced but suspension travel is increased.

Increasing damping coefficient reduces car body displacement and suspension travel considerably but vertical acceleration increases whereas an increase in the stiffness of vehicle suspension leads to an increase in vertical acceleration. The suspension travel shows an increase and decrease pattern.

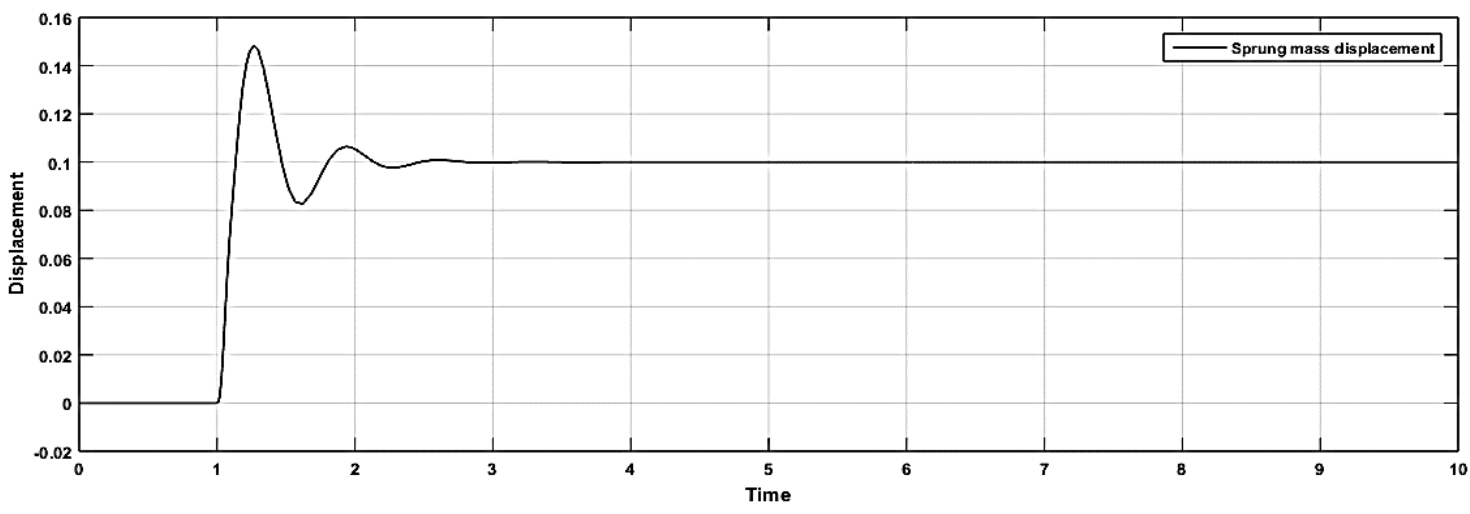

Figure 13. Displacement of sprung mass of half car model

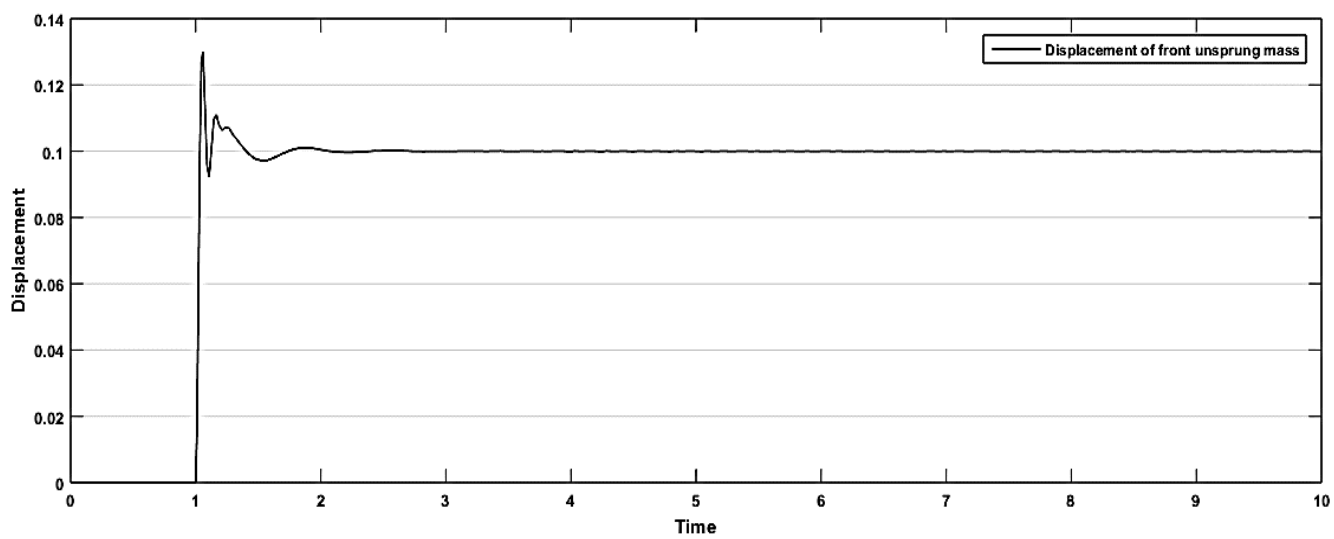

Figure 14. Displacement of front unsprung mass

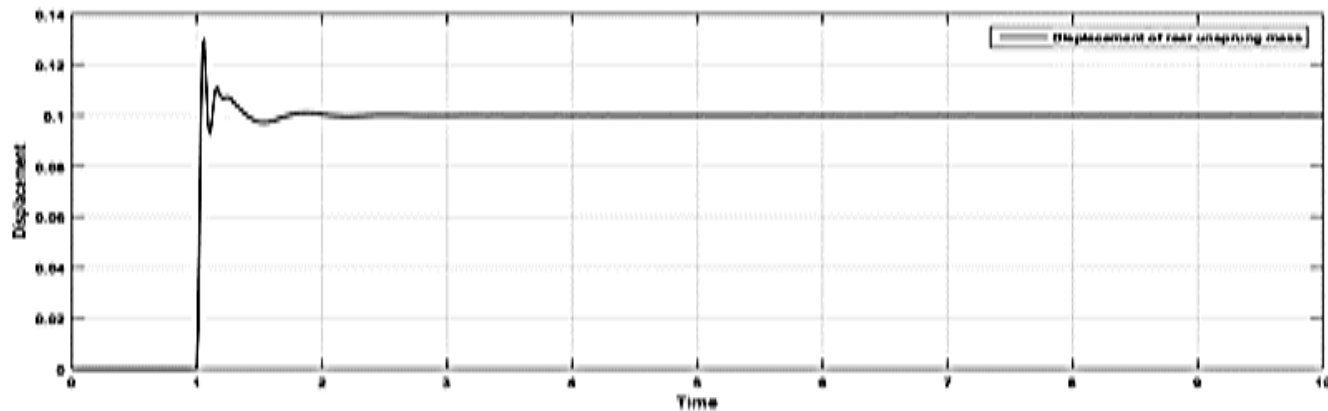

Figure 15. Displacement of rear unsprung mass 
Table 4. Simulation results for half car model

\begin{tabular}{|c|c|c|c|c|c|c|c|c|c|c|c|c|c|c|}
\hline \multirow[t]{2}{*}{ No } & \multirow{2}{*}{ Parameters } & \multirow{2}{*}{ Values } & \multirow{2}{*}{$\begin{array}{c}\text { Sprung } \\
\text { Mass } \\
\text { Displace }\end{array}$} & \multicolumn{2}{|c|}{$\begin{array}{c}\text { Unsprung Mass } \\
\text { Displacement }\end{array}$} & \multirow{2}{*}{\multicolumn{2}{|c|}{$\begin{array}{l}\text { Sprung Mass } \\
\text { Acceleration }\end{array}$}} & \multicolumn{4}{|c|}{ Suspension Travel } & \multicolumn{2}{|c|}{ Wheel Deflection } & \multirow{3}{*}{$\begin{array}{c}\text { RMS } \\
\begin{array}{c}\text { Accelerat } \\
\text { ion }\end{array} \\
3.80\end{array}$} \\
\hline & & & & Front & Rear & & & & & & & Front & Rear & \\
\hline 1 & \multirow{4}{*}{ Sprung Mass } & 400 & 0.148 & 0.1299 & 0.1301 & 32.034 & -10.685 & 0.0415 & -0.1045 & 0.0416 & -0.1046 & 0.0299 & 0.030 & \\
\hline 2 & & 500 & 0.151 & 0.1277 & 0.1278 & 26.057 & -7.295 & 0.0443 & -0.1074 & 0.0444 & -0.1075 & 0.0278 & 0.0278 & 3.080 \\
\hline 3 & & 1000 & 0.1602 & 0.1231 & 0.1235 & 13.539 & -2.434 & 0.0525 & -0.1137 & 0.0527 & -01138 & 0.0234 & 0.0236 & 1.595 \\
\hline 4 & & 1500 & 0.1652 & 0.1225 & 0.1226 & 9.129 & -1.697 & 0.0570 & -0.1159 & 0.0573 & -0.1160 & 0.0225 & 0.02258 & 1.102 \\
\hline 5 & \multirow{4}{*}{$\begin{array}{c}\text { Front } \\
\text { unsprung mass }\end{array}$} & 50 & 0.148 & 0.1361 & 0.1299 & 30.318 & -10.178 & 0.0419 & -0.1023 & 0.0421 & -0.1055 & 0.0361 & 0.0299 & 3.748 \\
\hline 6 & & 100 & 0.150 & 0.1485 & 0.1294 & 24.453 & -7.746 & 0.0471 & -0.0989 & 0.0434 & -0.1080 & 0.0485 & 0.0294 & 3.430 \\
\hline 7 & & 150 & 0.148 & 0.1567 & 0.1297 & 23.178 & -10.807 & 0.0613 & -0.0930 & 0.0424 & -0.1100 & 0.0568 & 0.0297 & 3.226 \\
\hline 8 & & 200 & 0.148 & 0.1607 & 0.1288 & 21.392 & -12.042 & 0.0747 & -0.0880 & 0.0438 & -0.1110 & 0.0677 & 0.0288 & 3.090 \\
\hline 9 & \multirow{4}{*}{$\begin{array}{c}\text { Rear unsprung } \\
\text { mass }\end{array}$} & 50 & 0.1482 & 0.1298 & 0.1360 & 30.292 & -10.172 & 0.0421 & -0.1054 & 0.0419 & -0.1020 & 0.0298 & 0.0362 & 3.748 \\
\hline 10 & & 100 & 0.1501 & 0.1292 & 0.1486 & 25.460 & -7.748 & 0.0432 & -0.1087 & 0.0474 & -0.0989 & 0.0292 & 0.0486 & 3.436 \\
\hline 11 & & 150 & 0.1480 & 0.1295 & 0.1569 & 23.179 & -10.823 & 0.0423 & -0.1090 & 0.0613 & -0.0939 & 0.0295 & 0.0569 & 3.227 \\
\hline 12 & & 200 & 0.1506 & 0.1286 & 0.1609 & 21.402 & -12.052 & 0.0438 & -0.1114 & 0.0747 & -0.0889 & 0.0286 & 0.0609 & 3.090 \\
\hline 13 & \multirow{4}{*}{$\begin{array}{c}\text { Front } \\
\text { suspension } \\
\text { stiffness }\end{array}$} & 21000 & 0.1483 & 0.1299 & 0.1301 & 32.034 & -10.685 & 0.0415 & -0.1045 & 0.0416 & -0.1046 & 0.0299 & 0.0300 & 3.801 \\
\hline 14 & & 30000 & 0.1523 & 0.1257 & 0.1312 & 32.306 & -9.342 & 0.0421 & -0.1000 & 0.0452 & -0.1036 & 0.0257 & 0.0312 & 3.917 \\
\hline 15 & & 40000 & 0.1547 & 0.1206 & 0.1315 & 33.043 & -9.524 & 0.0412 & -0.0958 & 0.0479 & -0.1028 & 0.0206 & 0.0315 & 4.056 \\
\hline 16 & & 50000 & 0.1565 & 0.1200 & 0.1317 & 33.924 & -10.805 & 0.0393 & -0.0919 & 0.0506 & -0.1023 & 0.0200 & 0.0317 & 4.179 \\
\hline 17 & \multirow{4}{*}{$\begin{array}{c}\text { Rear } \\
\text { suspension } \\
\text { stiffness }\end{array}$} & 21000 & 0.1483 & 0.1299 & 0.1301 & 32.034 & -10.085 & 0.0415 & -0.1045 & 0.0416 & -0.1046 & 0.0299 & 0.0300 & 3.801 \\
\hline 18 & & 30000 & 0.1521 & 0.1316 & 0.1267 & 32.203 & -9.607 & 0.0449 & -0.1014 & 0.0422 & -0.0985 & 0.03163 & 0.0267 & 3.967 \\
\hline 19 & & 40000 & 0.1545 & 0.1316 & 0.1212 & 32.461 & -9.477 & 0.0477 & -0.1022 & 0.0408 & -0.0956 & 0.03164 & 0.0212 & 4.071 \\
\hline 20 & & 50000 & 0.1559 & 0.1317 & 0.1202 & 33.609 & -10.772 & 0.0501 & -0.1019 & 0.0389 & -0.0919 & 0.0317 & 0.0202 & 4.188 \\
\hline 21 & \multirow{4}{*}{$\begin{array}{c}\text { Front } \\
\text { damping } \\
\text { coefficient }\end{array}$} & 1500 & 0.1483 & 0.1299 & 0.1301 & 32.034 & -10.085 & 0.0 .415 & -0.1045 & 0.0416 & -0.1046 & 0.0299 & 0.0300 & 3.801 \\
\hline 22 & & 2000 & 0.1440 & 0.1254 & 0.1318 & 33.159 & -10.669 & 0.0387 & -0.0922 & 0.0372 & -0.1011 & 0.0254 & 0.0318 & 4.102 \\
\hline 23 & & 2500 & 0.1406 & 0.1230 & 0.1320 & 34.671 & -11.702 & 0.0366 & -0.0847 & 0.0336 & -0.0997 & 0.0230 & 0.0322 & 4.272 \\
\hline 24 & & 3000 & 0.1375 & 0.1230 & 0.1314 & 35.598 & -12.669 & 0.0349 & -0.0800 & 0.0310 & -0.0986 & 0.0231 & 0.0314 & 4.498 \\
\hline 25 & \multirow{4}{*}{$\begin{array}{l}\text { Rear damping } \\
\text { coefficient }\end{array}$} & 1500 & 0.1484 & 0.1299 & 0.1300 & 32.034 & -10.685 & 0.0415 & -0.1045 & 0.0416 & -0.1046 & 0.0299 & 0.0300 & 3.807 \\
\hline 26 & & 2000 & 0.1440 & 0.1317 & 0.1255 & 33.148 & -10.684 & 0.0370 & -0.1011 & 0.0387 & -0.0922 & 0.03170 & 0.0255 & 4.100 \\
\hline 27 & & 2500 & 0.1405 & 0.1319 & 0.1233 & 34.548 & -11.761 & 0.0335 & -0.0995 & 0.0367 & -0.085 & 0.0317 & 0.0255 & 4.274 \\
\hline 28 & & 3000 & 0.0317 & 0.0319 & 0.1234 & 35.656 & -12.700 & 0.0308 & -0.0985 & 0.0350 & -0.0802 & 0.0317 & 0.0255 & 4.495 \\
\hline
\end{tabular}




\section{CONCLUSIONS}

In this work the effect of road excitations on a passive suspension for a passenger car was investigated. Mathematical modelling has been performed using a two and four degrees of freedom models. The differential equations of motion were simulated with Simulink/Matlab. The results from the simulation were used to analyse the performance of vehicle dynamics for step input road profile. The following conclusions are drawn. On the basis of the results, it can be concluded that road excitations affect the vehicle suspension which determines the ride comfort and stability of the vehicle.

\section{REFERENCES}

Agharkakli A., Ghobad Shafiei Sabet, Armin Barouz (2012). Simulation and Analysis of Passive and Active Suspension System using Quarter Car Model for Different Road Profile. International Journal of Engineering Trends and Technology, 3 (5).

Agostinacchio, M., Ciampa D. and Olita, S. (2014). The Vibration Induced by Surface Irregulation in Road pavementsa MATLAB Approach. Springer, 6, 267-275.

Changizi, N. and M. Rouhani, (2011). Comparing PID and Fuzzy Logic Control of a Quarter Car Suspension System. The Journal of Mathematics and Computer Science, 2(3), 559-564.

Gao, H; Xue,S; Yin,S; Qiu, J; Wang C. Output feedback control of multirate sampled-data systems with frequency specifications. IEEE Trans. control syst. technol. 2016

Ghazaly, N. M. and A. O. Moazz, (2014). The Future Development and Analysis of Vehicle Active Suspension System. IOSR Journal of Mechanical and Civil Engineering, 11(5), 19-25.

Kashem,S.B.A; Ektesabi, M.; Nagarajah, R. Comparison between different sets of suspension parameters and introduction of a new modified skyhook control strategy incorporating varying road condition. Vehicle Systems Dynamics. 2012.

Pedro, J. O. and J. E. D. Ekoru (2013). Proportional-integral derivative control of nonlinear half-car electro-hydraulic suspension systems. Journal of Zhejiang University-SCIENCE A (Applied Physics \& Engineering), 14(6), 401-416.

Turakhia T. P, Prof. M. J. Modi (2016). Mathematical Modeling and Simulation of a Simple Half - Car Vibration Model. International Journal for Scientific Research \& Development, 4(2), 2321-0613.

Williams R.A, (1994). Electronically controlled automotive suspensions. Computing \& Control Engineering Journal, 5(3), 143-148.

\section{LIST OF ABBREVIATIONS}

$M_{S}=$ sprung mass of vehicle

$M_{u f}=$ unsprung mass of front axle

$M_{u r}=$ unsprung mass of rear axle

$K_{u f}=$ suspension stiffness of front axle

$K_{u r}=$ suspension stiffness of rear axle

$C_{s f}=$ damping coefficient of front axle

$C_{s r}=$ damping coefficient of rear axle

$K_{t f}=$ stiffness of front tire

$K_{t r}=$ stiffness of rear tire

$\mathrm{L}=$ length of wheelbase

$\mathrm{b}=$ distance to front axle from centre of gravity

$\mathrm{C}=$ distance to rear axle from centre of gravity

$\theta=$ pitch angle

$Z_{r f}=$ road excitation at the front wheel

$Z_{r r}=$ road excitation at the rear wheel 